\title{
ChemComm
}

\section{Solid phase click ligation for the synthesis of very long oligonucleotides $\dagger$}

Cite this: Chem. Commun., 2013, 49, 6959

Received 4th April 2013,

Accepted 21st June 2013

DOI: $10.1039 / \mathrm{c} 3 \mathrm{cc} 42451 \mathrm{k}$

\author{
Jieqiong Qiu, ${ }^{a}$ Afaf H. El-Sagheer ${ }^{\mathrm{ab}}$ and Tom Brown*a
}

www.rsc.org/chemcomm

Oligonucleotides have been ligated efficiently on solid-phase using CUAAC and SPAAC chemistry to produce up to 186-mer triazole linked DNA products. Multiple sequential ligation reactions can be carried out by using a masked azide approach. This work suggests a novel modular approach to the synthesis of large complex oligonucleotide analogues.

The standard approach to the chemical synthesis of DNA is the highly efficient solid-phase phosphoramidite method. ${ }^{1}$ It can be used to assemble oligonucleotides over 100 bases in length, beyond which limitations in the chemistry make it difficult to produce pure DNA. An approach to the synthesis of larger DNA strands is to combine solid-phase oligonucleotide synthesis with chemical ligation, for example by using cyanogen bromide as a coupling agent. ${ }^{2,3}$ However, it remains challenging to achieve clean and efficient chemical ligation of oligonucleotides. An alternative strategy is to design a chemical linkage that mimics the natural phosphodiester and which can be formed efficiently and selectively. This has been achieved through a click chemistry approach ${ }^{4}$ in which the $\mathrm{Cu}^{\mathrm{I}}-$ catalysed [3+2] azide-alkyne cycloaddition (CuAAC) reaction ${ }^{5,6}$ is used to synthesise DNA containing biocompatible artificial linkages (Fig. 1a). An alternative copper-free DNA ligation method has recently been developed for applications in which it is not necessary to copy or amplify the sequence. ${ }^{7,8}$ This strategy takes advantage of the strain-promoted alkyne azide cycloaddition (SPAAC) reaction ${ }^{9}$ between azide and cyclooctyne-modified oligonucleotides (Fig. 1b). Both reactions are carried out in aqueous buffer in the presence of a complementary oligonucleotide template (splint) to hold the participating oligonucleotides in place. We now report a solid-phase strategy for ligating oligonucleotides using the CuAAC and SPAAC reactions. This approach has several desirable features; it is simple to carry out, the reaction can be forced to completion by adding an

\footnotetext{
${ }^{a}$ School of Chemistry, University of Southampton, Highfield, Southampton SO17 1BJ, UK. E-mail: tb2@soton.ac.uk; Fax: +44 (0)2380 592991; Tel: +44 (0)2380 592974

${ }^{b}$ Chemistry Branch, Dept. of Science and Mathematics, Suez University,

Suez 43721, Egypt

$†$ Electronic supplementary information (ESI) available: Experimental details for oligonucleotide synthesis, purification and labelling, click reactions, PAGE gels, full HPLC and mass spectra of click ligation reactions, table of oligonucleotide sequences and mass spec characterisation. See DOI: 10.1039/c3cc42451k
}

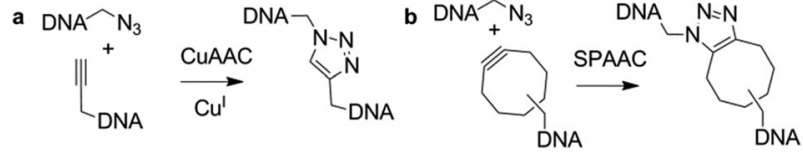

Fig. 1 CUAAC and SPAAC click reactions for DNA ligation.

excess of the solution-phase reactant, there is no requirement for a template oligonucleotide, and excess reagents can be conveniently removed and recovered.

The solid-phase CuAAC reaction has previously been used to synthesise short oligonucleotides with $5^{\prime}-5^{\prime}$-linkages. ${ }^{10}$ In the present work it was investigated for the synthesis of long oligonucleotides containing the biocompatible triazole linkage tz1 (Scheme 1c) which has applications in gene synthesis. ${ }^{11,12}$ The requisite $5^{\prime}$-azide oligonucleotides (ON1, 2, 5) were prepared on solid support by incorporating $5^{\prime}$-iodo-dT phosphoramidite monomer in the final coupling step followed by displacement of iodine with azide ${ }^{13}$ (Scheme 1a). The corresponding 3'-alkyne oligonucleotides (ON3, ON7) were prepared using protected 3'-O-propargyl-5-methyldeoxycytidine solid support, ${ }^{11}$ after which they were cleaved from the resin, deprotected and purified by HPLC (Scheme 1b). The reaction between a $5^{\prime}$-azide labelled oligonucleotide on the solid support and a $3^{\prime}$-alkyne labelled oligonucleotide in solution (Scheme 1c) were conducted on a $2 \mathrm{nmol}$ scale.

The resin-bound 17-mer azide oligonucleotide (Table 1) was made on cpg support of two different pore sizes; $1000 \AA$ (ON1) and $3000 \AA$ (ON2). It was reacted with 3 equivalents of $3^{\prime}$-alkynelabelled 10-mer $\mathrm{ON} 3$ in aqueous $\mathrm{CuSO}_{4}$, ascorbate, $\mathrm{Cu}^{\mathrm{I}}$-binding ligand (Scheme 1) and 50\% v/v of DMF. In both cases the reaction was complete within $7 \mathrm{~h}$ at $70{ }^{\circ} \mathrm{C}$ or $21 \mathrm{~h}$ at $40{ }^{\circ} \mathrm{C}$ (Table 2 and Fig. 2a) to give the triazole product (ON4) in high purity ( $~ 90 \%)$. No significant difference was observed between the reactions using the two different resin pore sizes, and $3000 \AA$ resin was used for further conjugations involving long oligonucleotides.

Next a much longer support-bound oligonucleotide (ON5, 61-mer) was conjugated to ON3 under similar conditions. The reaction was complete in $21 \mathrm{~h}$ at $55^{\circ} \mathrm{C}$ and the 72-mer (ON6) was obtained in good yield after cleavage from the resin and deprotection (Fig. 2b). 


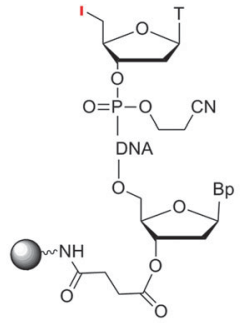

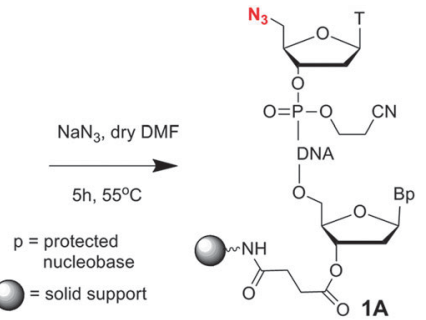

$1 \mathrm{~A}$
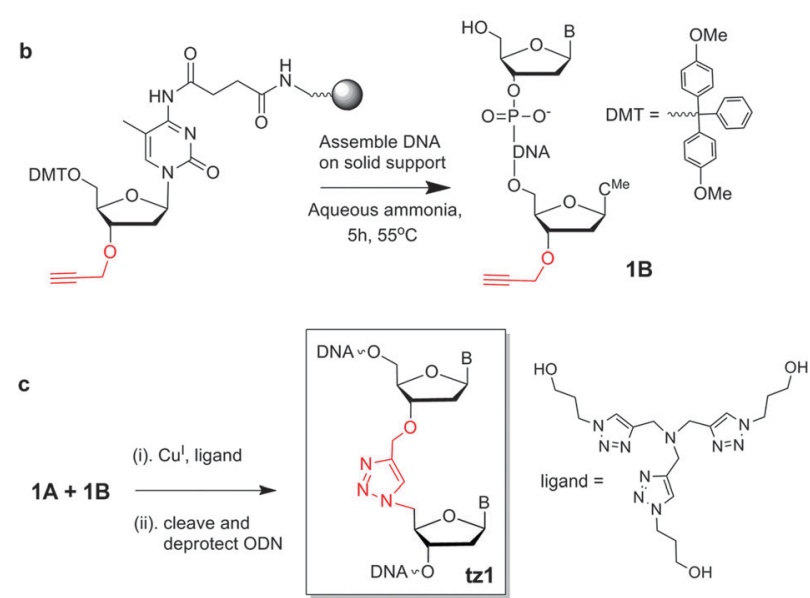

Scheme 1 Synthesis of biocompatible triazole linked oligonucleotides on solidphase.

Table 1 Oligonucleotides used in this study. For CuAAC reactions: (Scheme 1). $X=3^{\prime}$-propargyl 5-MedC, $5^{\prime} \mathrm{N}_{3}=5^{\prime}$-azido, tz $1=$ biocompatible triazole. For SPAAC reactions (Fig. 3): $5^{\prime}-\mathrm{BCN}$ is added using phosphoramidite $2,3^{\prime}-\mathrm{BCN}$ is made from $1+4,3^{\prime}-\mathrm{N}_{3}$ is made from $3+4$. Structures of $\mathrm{tz} 2, \mathrm{tz} 3, \mathrm{tz} 4,1$, and 4 are in Fig. 3

\begin{tabular}{|c|c|c|c|}
\hline Code & Sequence $\left(5^{\prime}-3^{\prime}\right)$ & Code & Sequence $\left(5^{\prime}-3^{\prime}\right)$ \\
\hline ON1 & $5^{\prime} \mathrm{N}_{3}-17$ mer-1000 Å resin & ON13 & $5^{\prime} \mathrm{BCN}-60 \mathrm{mer}-3000 \AA$ A resin \\
\hline ON2 & $5^{\prime} \mathrm{N}_{3}-17$ mer-3000 Å resin & ON14 & 60 mer- $\mathrm{N}_{3} 3^{\prime}$ \\
\hline ON3 & 10-mer-X & ON15 & ON13-tz3-ON14 \\
\hline ON4 & ON1/2-tz1-ON3 & ON16 & $5^{\prime} \mathrm{I}-60$ mer- $\mathrm{N}_{3} 3^{\prime}$ \\
\hline ON5 & $5^{\prime} \mathrm{N}_{3}-61 \mathrm{mer}-3000 \AA \AA$ resin & ON17a & $5^{\prime} \mathrm{I}-\mathrm{ON} 16-\mathrm{tz} 3-\mathrm{ON} 13$ \\
\hline ON6 & ON3-tz1-ON5 & ON17b & $5^{\prime} \mathrm{N}_{3}-\mathrm{ON} 16-\mathrm{tz} 3-\mathrm{ON} 13$ \\
\hline ON7 & 59mer-X & ON18 & ON17b-tz2-ON11 \\
\hline ON8 & ON1-tz1-ON7 & ON19 & $5^{\prime} \mathrm{I}-25$ mer- $\mathrm{N}_{3} 3^{\prime}$ \\
\hline ON9 & 11mer-BCN3' & ON20a & $5^{\prime} \mathrm{I}-\mathrm{ON} 19-\mathrm{tz} 3-\mathrm{ON} 13$ \\
\hline ON10 & ON1-tz2-ON9 & $\mathrm{ON} 20 \mathrm{~b}$ & $5^{\prime} \mathrm{N}_{3}-\mathrm{ON} 19-\mathrm{tz} 3-\mathrm{ON} 13$ \\
\hline ON11 & 66mer-BCN $3^{\prime}$ & ON21 & ON20b-tz2-ON11 \\
\hline ON12 & ON1-tz2-ON11 & ON22 & ON5-tz4-ON13 $\left(5^{\prime}-5^{\prime}\right.$-link $)$ \\
\hline
\end{tabular}

Table 2 Solid-phase CuAAC reaction between $3^{\prime}$-alkyne ONs and supportbound $5^{\prime}$-azide ONs. Products characterised by $\mathrm{MS}\left(\mathrm{ES}^{-}\right)$. Full conditions in ESI

\begin{tabular}{lllrrlllr}
\hline $\begin{array}{l}\text { Azide } \\
\text { ON }\end{array}$ & $\begin{array}{l}\text { Alkyne } \\
\text { ON }\end{array}$ & $\begin{array}{l}\text { Alkyne } \\
\text { eq. }\end{array}$ & \multicolumn{2}{c}{$\begin{array}{l}\text { Time } \\
\text { hours }\end{array}$} & $\begin{array}{l}\text { Product } \\
\text { code }\end{array}$ & Length & $\begin{array}{l}\text { MS } \\
\text { calc. }\end{array}$ & \multicolumn{1}{l}{$\begin{array}{l}\text { MS } \\
\text { found }\end{array}$} \\
\hline ON1 & ON3 & 3 & 70 & 7 & ON4 & 28 & 8403 & 8402 \\
ON1 & ON3 & 3 & 40 & 21 & ON4 & 28 & 8403 & 8402 \\
ON2 & ON3 & 3 & 70 & 7 & ON4 & 28 & 8403 & 8402 \\
ON2 & ON3 & 3 & 40 & 21 & ON4 & 28 & 8403 & 8402 \\
ON5 & ON3 & 3 & 55 & 21 & ON6 & 72 & 22232 & 22232 \\
ON1 & ON7 & 10 & 70 & 16 & ON8 & 77 & 23579 & 23579
\end{tabular}

The reaction at $40{ }^{\circ} \mathrm{C}$ did not quite proceed to completion, even after $21 \mathrm{~h}$. Similar results were obtained when the reaction was carried out using the shorter azide oligonucleotide on solid-phase (ON1) and the long 3 '-alkyne oligonucleotide (59-mer ON7) to give ON8. Further

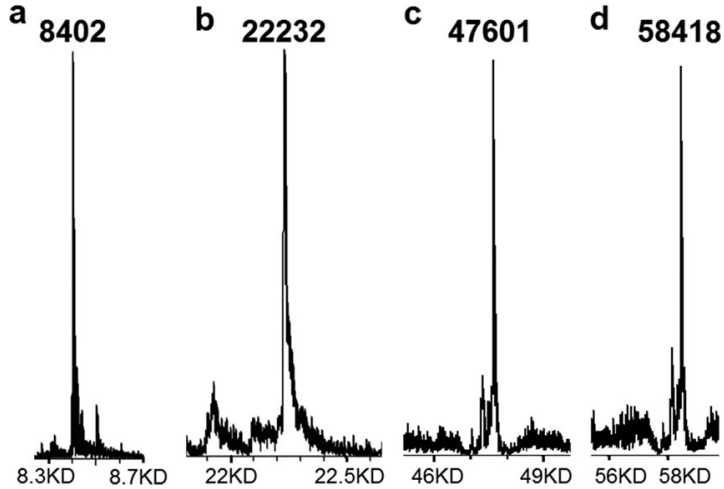

Fig. 2 ES $^{-}$MS of click-ligated oligonucleotides. (a) ON4, (b) ON6, (c) ON21 and (d) ON18. Full HPLC chromatograms and mass spectra are shown in ESI. $\dagger$

experiments confirmed that the optimum reaction conditions were 10 eq. of the alkyne oligonucleotide at $70{ }^{\circ} \mathrm{C}$ for $16 \mathrm{~h}$. Higher temperatures and longer times led to some $\mathrm{Cu}^{\mathrm{I}}$-catalysed oligonucleotide degradation despite the presence of the tris-hydroxypropyltriazolide ligand $^{14}$ (Scheme 1c).

For applications in which there is no requirement for polymerase enzymes to read through the triazole linkage the SPAAC reaction is an excellent alternative; it is extremely fast and does not require $\mathrm{Cu}^{\mathrm{I}}$ catalysis. The highly active symmetric bicycle [6.1.0] non-4-yne $(\mathrm{BCN})^{15}$ was used as the strained alkyne component to avoid diastereomers or regioisomers of the triazole products. It has recently been used for solution-phase oligonucleotide crosslinking and fluorescent labelling. ${ }^{8}$ Dibenzocyclooctyne (DIBO) was also found to be a suitable alkyne in solid-phase SPAAC ligation reactions, but gave the expected regio/stereoisomers (ESI $\dagger$ ).

BCN was attached post-synthetically to several 3'-amino-C7labeled oligonucleotides 4 using BCN NHS carbonate 1 (Fig. 3a). Support-bound azide ON1 was reacted with ON9 in a 1:1 ratio for $21 \mathrm{~h}$ at $40{ }^{\circ} \mathrm{C}$, to give quantitative conversion to the triazole ligation product ON10. A conjugation reaction was then conducted between 3'-BCN 66-mer (ON11) and 5'-azide oligonucleotide on resin (ON1). After $21 \mathrm{~h}$ at $40{ }^{\circ} \mathrm{C}$ the reaction proceeded to completion to give ON12. Next a solution-phase $3^{\prime}$-azide oligonucleotide was reacted with a support-bound $5^{\prime}$-BCN oligonucleotide. The required $3^{\prime}$-azide oligonucleotide (ON14) was synthesized by coupling azidohexanoic acid NHS ester 3 (ref. 16) to the $3^{\prime}$-amino-C7 oligonucleotide precursor 4 (Fig. 3a), and to prepare the support-bound 60-mer alkyne oligonucleotide (ON13), BCN phosphoramidite (2, Fig. 3a) was added to the $5^{\prime}$-terminus during solid-phase synthesis. This was reacted with 60-mer ON14 in aqueous solution (1.5 eq.) for $21 \mathrm{~h}$ at $40{ }^{\circ} \mathrm{C}$, resulting in the efficient formation of 120-mer ON15 containing triazole backbone tz3 (Fig. 3c and Table 3).

The success of the solid-phase SPAAC reaction to ligate two long oligonucleotides suggests that multiple SPAAC ligation reactions might be possible (Fig. 4). This requires the use of solution-phase oligonucleotides containing azide at each end. To control the regioselectivity of this reaction and prevent the formation of a $5^{\prime}-$ $5^{\prime}$ linkage it was necessary to mask the $5^{\prime}$-azide function. To achieve this, ON16 and ON19 were synthesized with $5^{\prime}$-iodo-dT and $3^{\prime}$-azide (derived from $3+4$, Fig. 3a) using fast-deprotection $\mathrm{A}, \mathrm{G}$ and $\mathrm{C}$ monomers (ESI $\dagger$ ). The oligonucleotides were cleaved from the resin and deprotected in ammonia at room temperature for $5 \mathrm{~h}$ to 
a<smiles>C[C@@H]1CC=CCC[C@@H]1COC(=O)ON1C(=O)CCC1=O</smiles>

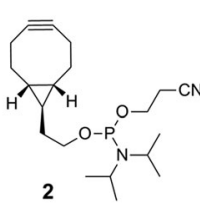
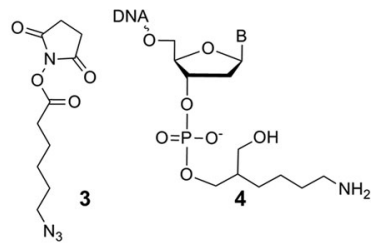

b DNA
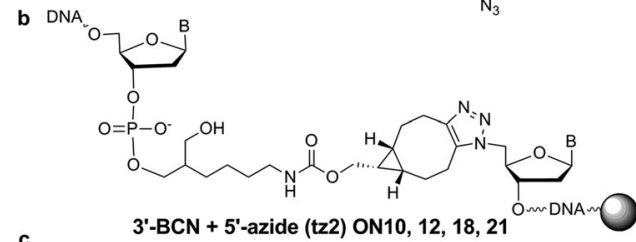
DNA<smiles></smiles>

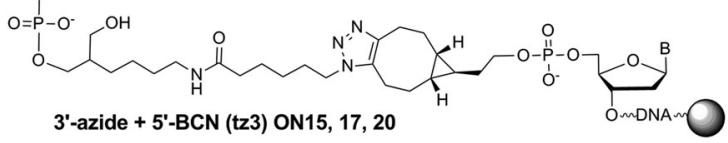

d

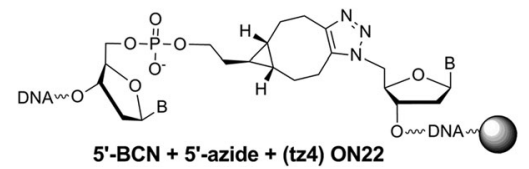

Fig. 3 Reagents and products of SPAAC ligation reactions. BCN reagents 1 and 2 from Berry Associates, for azide NHS ester 3 see ref. 16.

Table 3 Solid-phase SPAAC reactions in 10\% pyridine in water, $21 \mathrm{~h}$ reaction time at $40{ }^{\circ} \mathrm{C}$. Products characterised by MS (ES $\left.{ }^{-}\right)$. Full conditions in ESI

\begin{tabular}{|c|c|c|c|c|c|c|}
\hline $\begin{array}{l}\text { Azide } \\
\text { ON }\end{array}$ & $\begin{array}{l}\text { Alkyne } \\
\text { ON }\end{array}$ & $\begin{array}{l}\text { Solution } \\
\text { ON eq. }\end{array}$ & $\begin{array}{l}\text { Product } \\
\text { code }\end{array}$ & Length & $\begin{array}{l}\text { MS } \\
\text { calc. }\end{array}$ & $\begin{array}{l}\text { MS } \\
\text { found }\end{array}$ \\
\hline ON1 & ON9 & 1.0 & ON10 & 28 & 8735 & 8736 \\
\hline ON1 & ON11 & 1.0 & ON12 & 83 & 25845 & 25846 \\
\hline ON14 & ON13 & 1.5 & ON15 & 120 & 37617 & 37618 \\
\hline ON16 & ON13 & 3.0 & ON17b & 120 & 37615 & 37615 \\
\hline ON17b & ON11 & 3.0 & ON18 & 186 & 58417 & 58418 \\
\hline ON19 & ON13 & 3.0 & ON20b & 85 & 26798 & 26798 \\
\hline ON20b & ON11 & 3.0 & ON21 & 151 & 47600 & 47601 \\
\hline ON5 & ON13 & 3.0 & ON22 & 121 & 37641 & 37642 \\
\hline
\end{tabular}

preserve the integrity of the $5^{\prime}$-iodo group. They were then individually conjugated in a $3: 1$ ratio to the support-bound 60-mer ON13 to give triazole products ON17a and ON20a attached to the solid support. The $5^{\prime}$-iodo group was then displaced on solid phase by

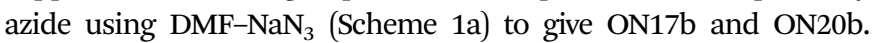
ON11 was then reacted with these click-linked oligonucleotides on solid support. Cleavage and deprotection gave the full length 151mer and 186-mer products ON21 and ON18 (Fig. 2c, d and 4). Finally the solid-phase synthesis of $5^{\prime}-5^{\prime}$-linked oligonucleotides was demonstrated by ligation of ON5 on solid support to ON13 in solution to give 121-mer ON22. It is noteworthy that in solid-phase SPAAC ligation reactions it is possible to recover the unreacted solution-phase oligonucleotide for re-use simply by lyophilisation.

Conditions for the solid-phase ligation of oligonucleotides by the CuAAC and SPAAC reactions have been developed which allow the efficient assembly of oligonucleotides up to 186 bases in length. Multiple sequential ligation reactions can be carried out with no requirement for a template oligonucleotide. This solid-phase method

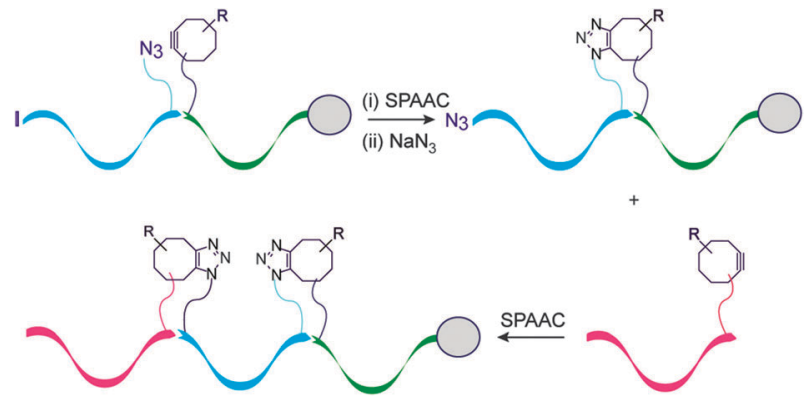

Fig. 4 Double sequential SPAAC ligation reactions using $5^{\prime}$-iodo as a masked 5'-azide to synthesise 186-mer ON18 and 151-mer ON21.

should be valuable for the synthesis of oligonucleotides conjugated to DNA analogues such as PNA. Many other applications can be envisaged, e.g. the synthesis of libraries of oligonucleotides which all have different 3 -sections (PCR primer or probe elements) but the same $5^{\prime}$-section, e.g. regions that contains several expensive fluorescent dyes or other complex modifications. The individual $3^{\prime}$-parts could be made on a small scale on solid-phase with a $5^{\prime}$-BCN attachment, and the $5^{\prime}$-part could be made on a large scale with a $3^{\prime}$-azide. The purified $3^{\prime}$-azide oligonucleotide could then be clicked to all the different resin bound $3^{\prime}$-components to give a library of oligonucleotides. If this is intended for use as a cocktail of probes in applications such as fluorescence in situ hybridization (FISH), all the resin-bound $3^{\prime}$-components can be mixed and ligated to the $5^{\prime}$-component in a single SPAAC reaction. We envisage that the methodology presented here will also be invaluable for the synthesis of very long modified oligonucleotides with complex 3-D architectures for use in various nanotechnology applications.

This research was funded by the BBSRC sLOLA grant BB/J001694/1 "Extending the boundaries of nucleic acid chemistry."

\section{Notes and references}

1 M. H. Caruthers, Acc. Chem. Res., 1991, 24, 278-284.

2 N. I. Sokolova, D. T. Ashirbekova, N. G. Dolinnaya and Z. A. Shabarova, Bioorg. Khim., 1987, 13, 1286-1288.

3 K. J. Luebke and P. B. Dervan, J. Am. Chem. Soc., 1991, 113, 7447-7448.

4 H. C. Kolb, M. G. Finn and K. B. Sharpless, Angew. Chem., Int. Ed., 2001, 40, 2004-2021.

5 V. V. Rostovtsev, L. G. Green, V. V. Fokin and K. B. Sharpless, Angew. Chem., Int. Ed., 2002, 41, 2596-2599.

6 C. W. Tornoe, C. Christensen and M. Meldal, J. Org. Chem., 2002, 67, 3057-3064.

7 M. Shelbourne, X. Chen, T. Brown and A. H. El-Sagheer, Chem. Commun., 2011, 47, 6257-6259.

8 M. Shelbourne, T. Brown and A. H. El-Sagheer, Chem. Commun., 2012, 48, 11184-11186.

9 J. C. Jewett and C. R. Bertozzi, Chem. Soc. Rev., 2010, 39, 1272-1279.

10 M. Alvira and R. Eritja, Chem. Biodiversity, 2007, 4, 2798-2809.

11 A. H. El-Sagheer, A. P. Sanzone, R. Gao, A. Tavassoli and T. Brown, Proc. Natl. Acad. Sci. U. S. A., 2011, 108, 11338-11343.

12 A. P. Sanzone, A. H. El-Sagheer, T. Brown and A. Tavassoli, Nucleic Acids Res., 2012, 40, 10567-10575.

13 G. P. Miller and E. T. Kool, Org. Lett., 2002, 4, 3599-3601.

14 T. R. Chan, R. Hilgraf, K. B. Sharpless and V. V. Fokin, Org. Lett., 2004, 6, 2853-2855.

15 J. Dommerholt, S. Schmidt, R. Temming, L. J. A. Hendriks, F. Rutjes, J. C. M. van Hest, D. J. Lefeber, P. Friedl and F. L. van Delft, Angew. Chem., Int. Ed., 2010, 49, 9422-9425.

16 C. Grandjean, A. Boutonnier, C. Guerreiro, J. M. Fournier and L. A. Mulard, J. Org. Chem., 2005, 70, 7123-7132. 